\title{
Separation and Recovery of SiC Particles Discharged from Silicon Wafer Production Process
}

\author{
Junji Shibata* and Norihiro Murayama
}

\author{
Department of Chemical, Energy and Environmental Engineering, Faculty of Environmental and Urban \\ Engineering, Kansai University, 3-3-35 Yamate-cho, Suita, Osaka, 564-8680, Japan
}

\begin{abstract}
In the slicing process of silicon wafer from silicon single crystal, it has been the general way to cut silicon by wire saws with the lubricant mixture of silicon carbide, as $\mathrm{SiC}$, particles and wrapping oil. After slicing the silicon single crystal, the waste liquor containing $\mathrm{SiC}$ and silicon powders is discharged from the process. The particle sizes of $\mathrm{SiC}$ and Si are about $10 \mu \mathrm{m}$ and $1 \mu \mathrm{m}$, respectively and the weight ratio is about 9:1. The particles discharged from slicing waste liquor become the mixture of $\mathrm{SiC}$ and $\mathrm{SiO}_{2}$, when the waste liquor is burned after treating the lubricant oil by a filter press. In terms of the minimization of wastes and environment, it is preferable to separate and recover the valuable $\mathrm{SiC}$ from $\mathrm{SiO}_{2}$.

In order to solve the problem mentioned above, flotation method can be applied to accomplish the separation of SiC from $\mathrm{SiO}_{2}$. The cationic surfactants of dodecyl-tri-methyl-ammonium chloride (abbreviated as DTMAC hereafter) and trimethyl-octyl-ammonium chloride (abbreviated as TMOAC hereafter) were used in this study. The adsorption amount of surfactants on $\mathrm{SiC}$ and $\mathrm{SiO}_{2}$ particles was measured. The flotation behaviors of $\mathrm{SiC}$ and $\mathrm{SiO}_{2}$ were investigated by changing $\mathrm{pH}$, gas flow rate and flotation time in the presence of DTMAC. The purity and yield of SiC were also discussed in the flotation process comprising of roughing, cleaning and scavenging steps. A series of flotation process for $\mathrm{SiC}$ gave the purity and yield of $99.7 \%$ and $96.7 \%$, respectively.
\end{abstract}

Keywords: Flotation, $\mathrm{SiC}, \mathrm{SiO}_{2}$, silicon wafer slicing waste, TMOAC, DTMAC.

\section{INTRODUCTION}

Silicon carbide is used as grinding and cutting materials, refractory and semiconductor. It has a fireresistant property and is stable up to $1873 \mathrm{~K}$ in air. The hardness is in the order of diamond $>$ Boron carbide > $\mathrm{SiC}>$ alumina.

It has been the general way to cut silicon by wire saws with the lubricant mixture of $\mathrm{SiC}$ particles and wrapping oil in the slicing process of silicon single crystal ingot. Since the slurry contains SiC particles in the slicing process, it has been an environmental issue to treat the discharged waste liquor containing $\mathrm{SiC}$ (particle size; about $10 \mu \mathrm{m}$ ) and Si (particle size; about $1 \mu \mathrm{m})$ with weight ratio of 9:1.

The powders in the slicing waste liquor become the mixture of $\mathrm{SiC}$ and $\mathrm{SiO}_{2}$ when the waste mixture is burned after treating the lubricant oil by a filter press. It is necessary to establish the process for separating valuable $\mathrm{SiC}$ from the waste liquor in terms of the minimization of wastes and environment. Specific gravity separation is not suitable for the separation of $\mathrm{SiC}$ and $\mathrm{SiO}_{2}$, since the specific gravity of both particles is very close. It is also difficult to separate $\mathrm{SiC}$ and $\mathrm{SiO}_{2}$ by using any cyclone, since both particles

*Address correspondence to this author at the Department of Chemical, Energy and Environmental Engineering, Faculty of Environmental and Urban Engineering, Kansai University, 3-3-35 Yamate-cho, Suita, Osaka, 564-8680, Japan; Tel: 81-6-6368-0856; Fax: 81-6-6388-8869;

E-mail: shibata@kansai-u.ac.jp have very small sizes. On the contrary, flotation is a preferable method which does not require the difference in specific gravity and particle size. Flotation takes place only by the surface property as a driving force for the separation [1-4]. Kusaka et al. reported the similarity of flotation behavior among $\mathrm{Si}, \mathrm{SiO}_{2}$ and $\mathrm{SiC}$ particles having average particle size under $1 \mu \mathrm{m}$ by using DTMAC. They also investigated the effect of cupper ion on the $\mathrm{SiC}$ flotation behavior $[5,6]$

In this study, the separation and recovery of SiC discharged in the slicing process of silicon wafer from silicon single crystal were carried out by a flotation method. Cationic surfactants were employed and the adsorption amounts of surfactants on $\mathrm{SiC}$ and $\mathrm{SiO}_{2}$ particles were measured. The flotation behavior of $\mathrm{SiC}$ and $\mathrm{SiO}_{2}$ was investigated by changing $\mathrm{pH}$, gas flow rate and flotation time in the presence of cationic surfactant. The purity and yield of SiC were also discussed in the flotation process comprising of roughing, cleaning and scavenging steps.

\section{EXPERIMENTAL}

\subsection{Reagent}

Silicon carbide used in this study was provided from Showa Denko K.K. The color is green and median particle size is $22 \mu \mathrm{m}$. Silicon dioxide was provided from Taki Chemical Co., Ltd. whose color is white and median particle size is $9.3 \mu \mathrm{m}$. Since both particles 
were prepared for this study, these particle sizes are larger than the actual particle sizes discharged from the slicing waste liquor. It is necessary to take account of the particle size effect in the flotation behavior, but in this case they will be enough size to carry out the flotation test.

For the measurements of the particle sizes and zeta potential, laser scattering particle size analyzer, LA910 (Horiba, Ltd.) and Zetasizer Nano Z (Malvern Instruments Ltd.) were used, respectively. Autosorb 1MP-LP2 (Quantachrome Instrument Co., Ltd.) was used to measure the specific surface areas of $\mathrm{SiC}$ and $\mathrm{SiO}_{2}$. The contact angles of $\mathrm{SiC}$ and $\mathrm{SiO}_{2}$ were measured by a contact angle meter Type Q1 (Kyowa Kaimenkagaku Co., Ltd.) after treating by a tablet shaping machine. Table $\mathbf{1}$ shows the physical properties of $\mathrm{SiC}$ and $\mathrm{SiO}_{2}$.

Table 1: Physical Properties of $\mathrm{SiC}$ and $\mathrm{SiO}_{2}$

\begin{tabular}{|c|c|c|}
\hline & SiC & SiO $_{2}$ \\
\hline \hline Median diameter $[\mu \mathrm{m}]$ & 22.2 & 9.3 \\
\hline Surface area $\left[\mathrm{m}^{2} / \mathrm{g}\right]$ & 0.4 & 121 \\
\hline Contact angle $[$ degree] & 37 & 84 \\
\hline
\end{tabular}

As cationic surfactants, TMOAC (Tokyo Chemical Industry, Co., Ltd.) and DTMAC (Tokyo Chemical Industry, Co.) were used in this study. Table 2 shows the chemical structure of TMOAC and DTMAC.

\subsection{Method}

As adsorption tests of surfactants on $\mathrm{SiC}$ and $\mathrm{SiO}_{2}$, several slurries were prepared with different solid contents and surfactant concentrations. The slurries were adjusted to be at the fixed $\mathrm{pH}$ and stirred for 15 minutes. After the configuration of the slurry samples, the concentrations of surfactants in the supernatant were determined by the Orange II method [7] and calculated the adsorbed amount of surfactants by the mass balance.
The flotation tests of $\mathrm{SiC}$ and $\mathrm{SiO}_{2}$ were carried out in the following manner. The flotation apparatus was made of PVC, and the column diameter and height were $\varphi 100 \mathrm{~mm}$ and $160 \mathrm{~mm}$, respectively. After preparing the slurries containing each particle and surfactant at a fixed $\mathrm{pH}$, the slurries were stirred for 15 minutes. Then, the slurries were transferred to the experimental apparatus and flotation tests were carried out by introducing $\mathrm{N}_{2}$ gas from the bottom through the glass filter and stirring at $300 \mathrm{rpm}$. In the flotation tests, pine oil of $20 \mathrm{ppm}$ was used as a frother. The recoveries of $\mathrm{SiC}$ and $\mathrm{SiO}_{2}$ were determined by the gravimetry method after the particles recovered in the froth were filtered, rinsed and dried up.

\section{RESULTS AND DISCUSSION}

\subsection{Adsorption of Cationic Surfactant for SiC and $\mathrm{SiO}_{2}$}

Figure 1 shows the zeta potential of $\mathrm{SiC}$ and $\mathrm{SiO}_{2}$ particles. The P.Z.C.s of $\mathrm{SiC}$ and $\mathrm{SiO}_{2}$ are located at the extremely acidic $\mathrm{pH}$ of 2.3 and 3.5 , respectively. Based on the zeta potential of these particles, TMOAC and DTMAC were employed as surfactants. The relationship between the adsorption amounts of cationic surfactants on $\mathrm{SiC}$ and $\mathrm{pH}$ is shown in Figure 2. When the $\mathrm{pH}$ is over P.Z.C., the adsorption amount of surfactant increases with an increase in $\mathrm{pH}$ and the adsorption amount reaches a constant value over $\mathrm{pH}$ 6.0. The dissociation of these surfactants produces positive ionic species in the solution. The zeta potential measurement shows that $\mathrm{SiC}$ particles are positively charged in the lower $\mathrm{pH}$ range, while in the higher $\mathrm{pH}$ range $\mathrm{SiC}$ particles are negatively charged. Additionally, it is considered that in the $\mathrm{pH}$ range over P.Z.C., the occurrence of strong electrostatic attractive force between $\mathrm{SiC}$ surface and cationic surfactant species results in the increase in the adsorption amount. The broken line in Figure 2 indicates the saturated monolayer adsorption $\left(1.1 \times 10^{-5} \mathrm{~mol} / \mathrm{m}^{2}\right)$ of DTMAC obtained by Langmuir plot based on the relationship between the adsorption amount and

Table 2: Cationic Surfactants Used in this Study

\begin{tabular}{|c|c|c|}
\hline & Trimethyloctylammonium Chloride (TMOAC) & Dodecyltrimethylammonium Chloride (DTMAC) \\
\hline Molecular weight & 208 & 264 \\
\hline Structural formula & {$\left[\begin{array}{c}\mathrm{CH}_{3} \\
\mathrm{I} \\
\mathrm{CH}_{3}\left(\mathrm{CH}_{2}\right)_{7}-\mathrm{N}-\mathrm{CH}_{3} \\
\mathrm{I} \\
\mathrm{CH}_{3}\end{array}\right]^{+} \cdot \mathrm{Cl}^{-}$} & {$\left[\begin{array}{c}\mathrm{CH}_{3} \\
\mathrm{I} \\
\mathrm{CH}_{3}(\mathrm{CH})_{11}-\mathrm{N}-\mathrm{CH}_{3} \\
\mathrm{I} \\
\mathrm{CH}_{3}\end{array}\right]^{+} \cdot \mathrm{Cl}^{-}$} \\
\hline
\end{tabular}


DTMAC concentration. It is considered from Figure 2 that the saturated monolayer adsorption of TMOAC is almost equal to that of DTMAC and also the adsorption amounts of both surfactants exceed the monolayer adsorption over $\mathrm{pH} \mathrm{6.0.} \mathrm{The} \mathrm{adsorption} \mathrm{isotherm} \mathrm{of} \mathrm{the}$ surfactants for $\mathrm{SiC}$ at $\mathrm{pH} 8.5$ is shown in Figure 3. The adsorption amounts of both cationic surfactants increase with an increase in their concentrations. The adsorption isotherms of TMOAC and DTMAC exhibit the same results; the saturated monolayer adsorption of cationic surfactants is obtained at the equilibrium concentration of $9.0 \times 10^{-4} \mathrm{~mol} / \mathrm{dm}^{3}$.

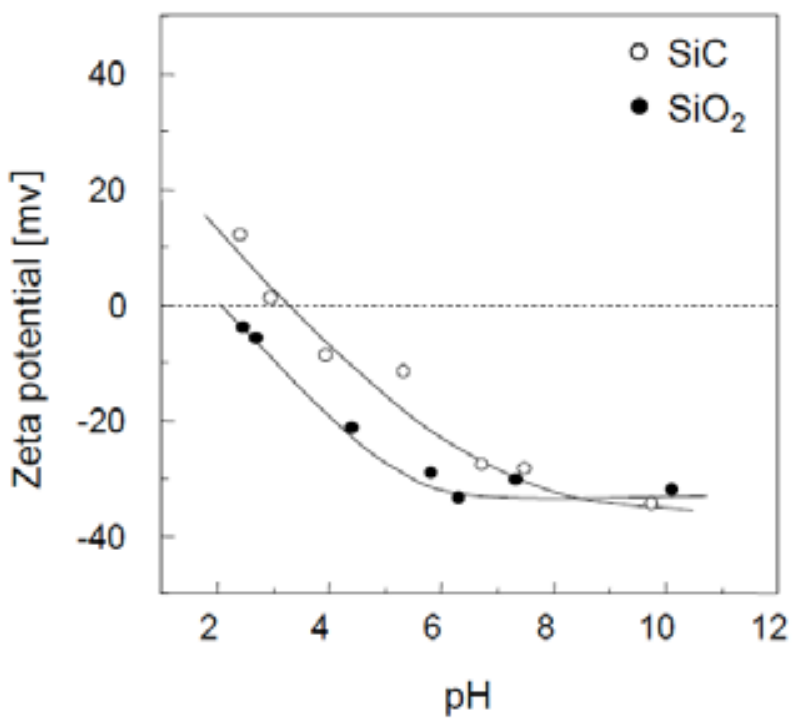

Figure 1: Zeta potential of $\mathrm{SiC}$ and $\mathrm{SiO}_{2}$ as a function of $\mathrm{pH}$.

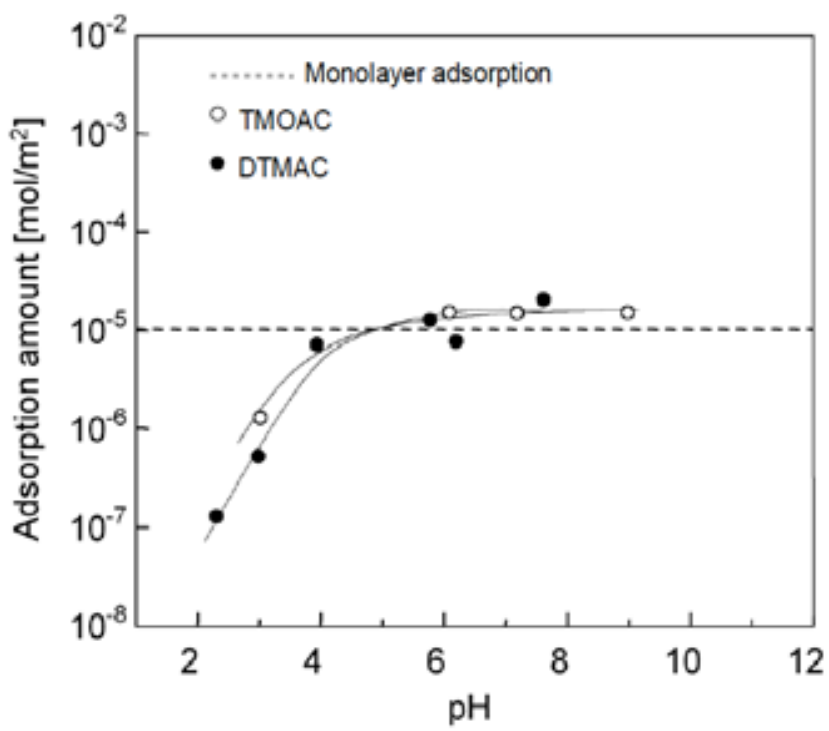

Figure 2: Adsorption amount of cationic surfactants on $\mathrm{SiC}$ as a function of $\mathrm{pH}$.

$\left(\begin{array}{l}\text { Solid content : } 0.3 \mathrm{wt} \% \\ \text { Surfactant concn. }: 9 \times 10^{-4} \mathrm{~mol} / \mathrm{dm}^{3}\end{array}\right)$

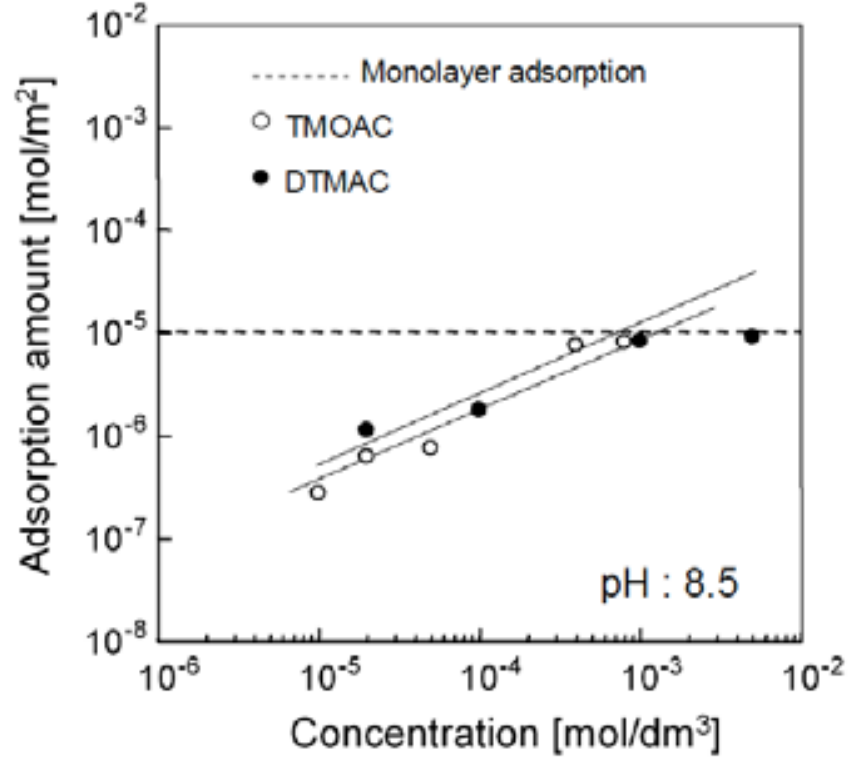

Figure 3: Adsorption isotherm of cationic surfactants on SiC. (Solid content: 0.3wt\%).

Figure 4 shows the relationship between the adsorption amount of cationic surfactants for $\mathrm{SiO}_{2}$ and $\mathrm{pH}$. Both surfactants give the small adsorption on $\mathrm{SiO}_{2}$ in the lower $\mathrm{pH}$ range, while the adsorption increases with increasing $\mathrm{pH}$. In any $\mathrm{pH}$ range, the adsorption amounts of TMOAC and DTMAC for $\mathrm{SiO}_{2}$ are less than the saturated monolayer adsorption. The broken line in the Figure 4 indicates the saturated monolayer adsorption $\left(3.7 \times 10^{-6} \mathrm{~mol} / \mathrm{m}^{2}\right)$ of DTMAC obtained by

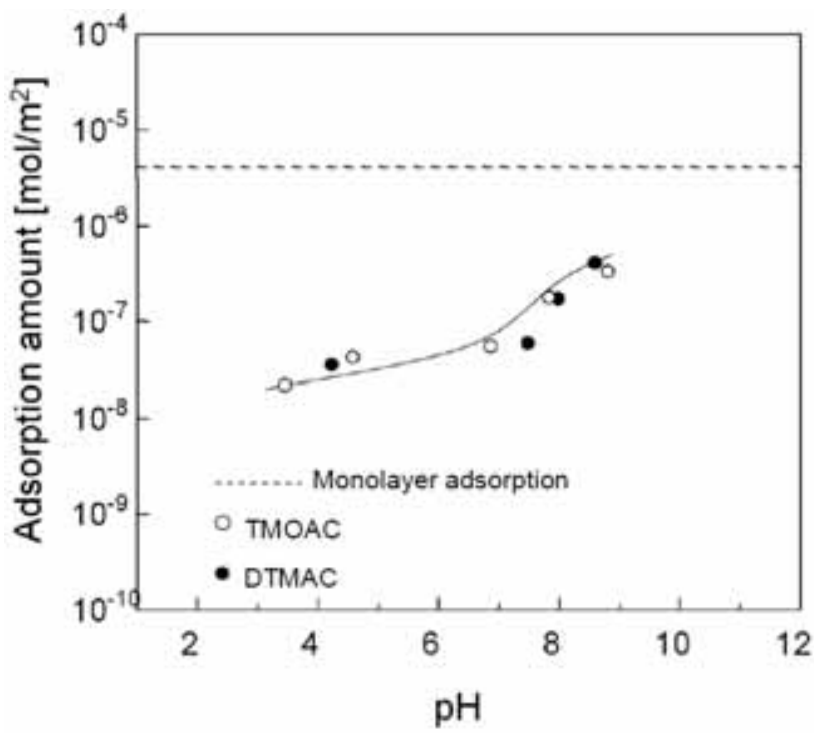

Figure 4: Adsorption amount of cationic surfactants on $\mathrm{SiO}_{2}$ as a function of $\mathrm{pH}$.

$$
\left(\begin{array}{l}
\text { Solid content : } 0.3 \mathrm{wt} \% \\
\text { TMOAC : } 10^{-4} \mathrm{~mol} / \mathrm{dm}^{3} \\
\text { DTMAC }: 9 \times 10^{-4} \mathrm{~mol} / \mathrm{dm}^{3}
\end{array}\right)
$$


Langmuir plot. The saturated monolayer adsorption of TMOAC is almost the same as that of DTMAC. Figure 5 shows the adsorption isotherms of DTMAC and TMOAC for $\mathrm{SiO}_{2}$ at $\mathrm{pH}$ 8.5. The adsorption amounts of both surfactants increase with increasing their concentrations. When the equilibrium concentration is $9.0 \times 10^{-4} \mathrm{~mol} / \mathrm{dm}^{3}$, the adsorption amount becomes to be $1.7 \times 10^{-7} \mathrm{~mol} / \mathrm{m}^{2}$. If the surface coverage is assumed to be unity at the saturated monolayer adsorption and this value is converted into the surface coverage, it would be a very small value; $1.7 \times 10^{-7}\left[\mathrm{~mol} / \mathrm{m}^{2}\right] / 3.7 \times 10^{-}$ ${ }^{6}\left[\mathrm{~mol} / \mathrm{m}^{2}\right]=0.046$. TMOAC and DTMAC exhibit very similar adsorption isotherms for $\mathrm{SiO}_{2}$. The reason for the similarity of adsorption isotherms is considered to be based on the fact that TMOAC and DTMAC are quaternary ammonium salts and they have similar molecular structures with only different hydrophobic group.

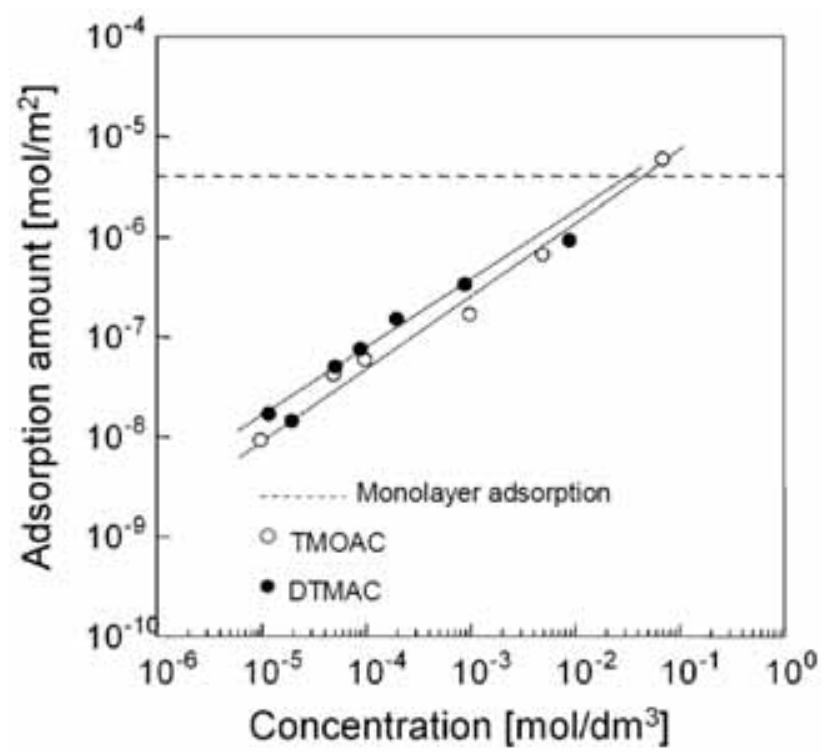

Figure 5: Adsorption isotherm of cationic surfactants on $\mathrm{SiO}_{2}$.

(Solid content: $0.3 \mathrm{wt} \%, \mathrm{pH}:$ 8.5).

\subsection{Flotation Separation of $\mathrm{SiC}$ and $\mathrm{SiO}_{2}$ with Cationic Surfactants}

The flotation tests were carried out for $\mathrm{SiC}$ and $\mathrm{SiO}_{2}$ independently with cationic surfactants. Figure 6 shows the flotation results with DTMAC. When TMOAC was employed for the flotation of $\mathrm{SiC}$ alone, the recovery percentages were $27 \%$ at $\mathrm{pH} 2.3$ and $38 \%$ at $\mathrm{pH} 9.0$. It is found that the flotation recovery of $\mathrm{SiC}$ with DTMAC is $30 \%$ at $\mathrm{pH} 3.1$ and the recovery increases with increasing $\mathrm{pH}$. When the $\mathrm{pH}$ value is 6.0 , the $78 \%$ recovery of $\mathrm{SiC}$ is obtained, while over $\mathrm{pH} 6.0$ the flotation recovery of $\mathrm{SiC}$ becomes almost constant.
This $\mathrm{pH}$ value agrees with the $\mathrm{pH}$ where the adsorption amount of surfactant for SiC becomes constant. The recovery difference occurred in these tests is based on the fact that DTMAC gives stronger hydrophobic property on SiC surface than TMOAC, because DTMAC has a longer alkyl carbon chain as a hydrophobic group than TMOAC.

When TMOAC is used as the surfactant, the recovery of $\mathrm{SiO}_{2}$ alone is less than $5 \%$ in any $\mathrm{pH}$ range. It follows from Figure 6 that in the case of DTMAC, the flotation recovery of $\mathrm{SiO}_{2}$ alone increases with an increase in $\mathrm{pH}$, e.g. $6.0 \%$ and $30 \%$ at $\mathrm{pH} 3.5$ and 8.5 , respectively. DTMAC brings the largest differences of flotation recovery of $\mathrm{SiC}$ and $\mathrm{SiO}_{2}$ at $\mathrm{pH}$ 6.0 , where the recoveries of $\mathrm{SiC}$ and $\mathrm{SiO}_{2}$ are $78 \%$ and $15 \%$, respectively. In the case of the flotation of $\mathrm{SiC}$ from $\mathrm{SiO}_{2}$, it is preferable to employ DTMAC as a surfactant.

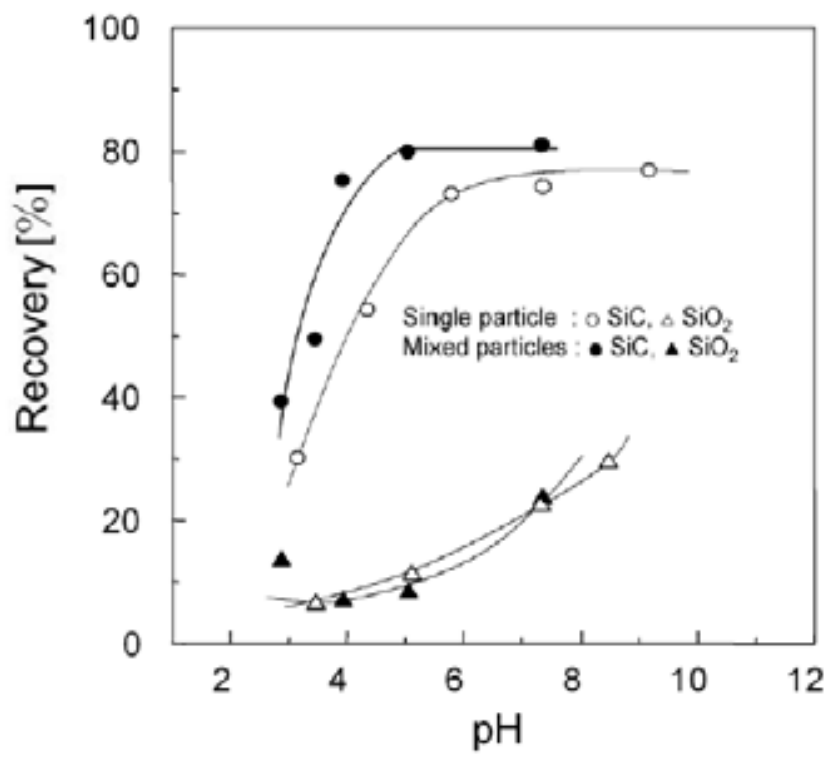

Figure 6: Flotation recovery of single and mixed particles with dodecyltrimethylammonium chloride as a function of $\mathrm{pH}$.

$\left(\begin{array}{l}\text { Solid content }: 0.3 \mathrm{wt} \%\left(\mathrm{SiC}: \mathrm{SiO}_{2}=9: 1\right. \\ \text { DTMAC concn. }: 9 \times 10^{-4} \mathrm{~mol} / \mathrm{dm}^{3} \\ \text { Flotation time }: 1.5 \mathrm{~min}\end{array}\right)$

The reason why the flotation recovery of $\mathrm{SiO}_{2}$ is smaller than that of $\mathrm{SiC}$ is possibly related to the surface coverage of the surfactant although the adsorption amount of surfactant on $\mathrm{SiO}_{2}$ is larger than that on SiC. As mentioned above, if the surface coverage is assumed to be unity when the adsorption is saturated in monolayer state, the coverage for $\mathrm{SiO}_{2}$ is 0.046 . Since the specific surface area of $\mathrm{SiO}_{2}$ is larger than that of $\mathrm{SiC}$, the small coverage of $\mathrm{SiO}_{2}$ is 
understandable even if the adsorption amount of surfactant on $\mathrm{SiO}_{2}$ is larger than that on $\mathrm{SiC}$. In this case, the surfactant coverage for SiC is unity or more than unity. From the comparison of the contact angles between $\mathrm{SiO}_{2}$ and $\mathrm{SiC}$ particles shown in Table 2, SiC surface has stronger hydrophobic property than $\mathrm{SiO}_{2}$ surface. Thus, it is considered that the difference of flotation recovery between $\mathrm{SiC}$ and $\mathrm{SiO}_{2}$ is related to the adsorption of surfactant and properties of the particles.

The flotation test for $\mathrm{SiC}$ and $\mathrm{SiO}_{2}$ mixture was carried out with DTMAC. Figure 6 also shows the relationship between the flotation recovery of $\mathrm{SiC}$ and $\mathrm{SiO}_{2}$ from the mixture, and $\mathrm{pH}$. The recovery of $\mathrm{SiC}$ is $40 \%$ at $\mathrm{pH} 3.0$, while $\mathrm{SiO}_{2}$ particles are recovered by $6 \%$ at the same $\mathrm{pH}$. The $\mathrm{SiC}$ recovery increases with increasing $\mathrm{pH}$ and $80 \%$ of $\mathrm{SiC}$ is recovered at $\mathrm{pH} 6.0$. Over $\mathrm{pH} \mathrm{6.0,} \mathrm{the} \mathrm{recovery} \mathrm{of} \mathrm{SiC}$ goes to constant. $\mathrm{SiO}_{2}$ particles are recovered with $6 \%$ at $\mathrm{pH}$ 3.0. Concerning $\mathrm{SiO}_{2}$, the recovery increases with increasing $\mathrm{pH}$ and $22 \%$ of $\mathrm{SiO}_{2}$ is recovered at $\mathrm{pH}$ 7.3. When $\mathrm{pH}$ value is 6.0 , there is the largest recovery difference between $\mathrm{SiC}$ and $\mathrm{SiO}_{2}$, where the recoveries are $80 \%$ and $10 \%$, respectively. Therefore, the preferable $\mathrm{pH}$ is 6.0 if $\mathrm{SiC}$ is separated from $\mathrm{SiO}_{2}$ using DTMAC by flotation.

Figure 7 shows the relationship between $\mathrm{N}_{2}$ gas flow rate and flotation recovery. From the viewpoint of separation, $\mathrm{pH}$ was fixed at 6.0 in this test. The constant $\mathrm{SiC}$ recovery of $80 \%$ was obtained regardless of gas flow rate, whereas $\mathrm{SiO}_{2}$ recovery depends on the gas flow rate. The $\mathrm{SiO}_{2}$ recovery increases with an increase in the gas flow rate and the recovery becomes about $8 \%$ at the gas flow rate of $200 \mathrm{~cm}^{3} / \mathrm{min}$. When the $\mathrm{N}_{2}$ gas flow rate is $200 \mathrm{~cm}^{3} / \mathrm{min}$, there is the largest recovery difference between $\mathrm{SiC}$ and $\mathrm{SiO}_{2}$. Figure 8 shows the relationship between the flotation time and recovery. When the flotation time is 5 minutes, SiC is recovered at $43 \%$. Thus, the recovery depends on the flotation time. Flotation more than 15 minutes results in the constant $\mathrm{SiC}$ recovery of $78 \%$. $\mathrm{SiO}_{2}$ recovery also depends on the flotation time, namely $8 \%$ for 0.5 minutes and $19 \%$ for 3 minutes, respectively. When the flotation time is 1.5 minutes, there is the largest recovery difference between $\mathrm{SiC}$ and $\mathrm{SiO}_{2}$. From these results, the preferable flotation operation conditions for the mixture of $\mathrm{SiC}$ and $\mathrm{SiO}_{2}$ are as follows; the $\mathrm{N}_{2}$ gas flow rate of $200 \mathrm{~cm}^{3} / \mathrm{min}$ and flotation time of 1.5 minutes.

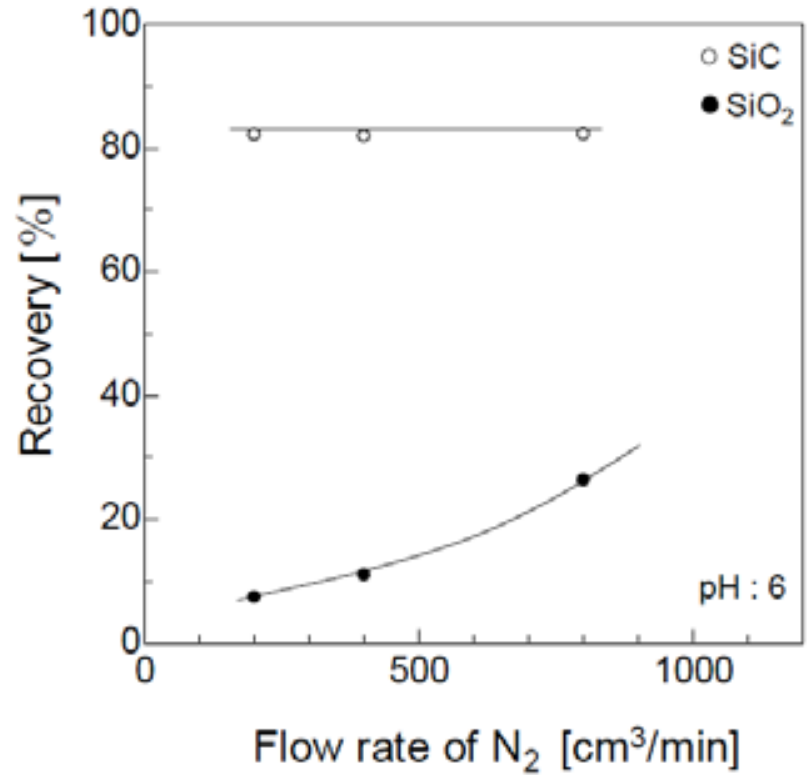

Figure 7: Relationship between flotation recovery and flow rate of $\mathrm{N}_{2}$ in case of dodecyltrimethylammonium chloride.

$\left(\begin{array}{l}\text { Solid content }: 0.3 \mathrm{wt} \%\left(\mathrm{SiC}: \mathrm{SiO}_{2}=9: 1\right. \\ \text { DTMAC concn.ion }: 9 \times 10^{-4} \mathrm{~mol} / \mathrm{dm}^{3} \\ \text { Flotation time }: 1.5 \mathrm{~min}\end{array}\right)$

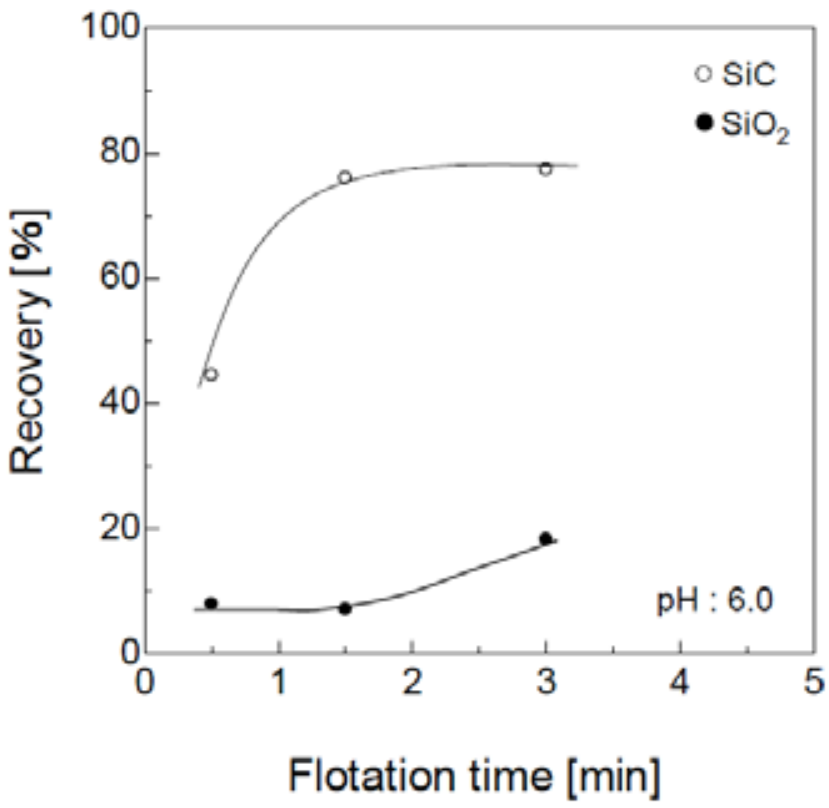

Figure 8: Relationship between flotation recovery and flotation time in case of dodecyltrimethylammonium chloride.

$\left(\begin{array}{l}\text { Solid content }: 0.3 \mathrm{wt} \%\left(\mathrm{SiC}: \mathrm{SiO}_{2}=9: 1\right. \\ \text { DTMAC concn. }: 9 \times 10^{-4} \mathrm{~mol} / \mathrm{dm}^{3} \\ \text { Flow rate of } \mathrm{N}_{2}: 200 \mathrm{~cm}^{3} / \mathrm{min}\end{array}\right)$

The flotation of $\mathrm{SiC}$ and $\mathrm{SiO}_{2}$ with DTMAC was carried out to clarify the dependency of the mixing ratio of $\mathrm{SiC}$ and $\mathrm{SiO}_{2}$, which may work efficiently for the 
separation of $\mathrm{SiC}$ and $\mathrm{SiO}_{2}$. In the mixing ratio of $\mathrm{SiC}$ and $\mathrm{SiO}_{2}$ of $10: 1,4: 1$ and $1: 1$, each flotation recovery increases with increasing $\mathrm{pH}$ and the recovery of $\mathrm{SiC}$ reaches the constant of $80 \%$ at $\mathrm{pH} 6.0$. On the other hand, the recovery of $\mathrm{SiO}_{2}$ is less than $30 \%$ in any $\mathrm{pH}$ range even though the $\mathrm{SiO}_{2}$ recovery increases with an increase in $\mathrm{pH}$. Therefore, the flotation with DTMC at $\mathrm{pH} 6.0$ makes it possible to separate $\mathrm{SiC}$ from $\mathrm{SiO}_{2}$.

The effect of DTMAC concentration on the flotation of $\mathrm{SiC}$ and $\mathrm{SiO}_{2}$ was investigated. When the DTMAC concentrations are $4.0 \times 10^{-4} \mathrm{~mol} / \mathrm{dm}^{3}$ and $1.6 \times 10^{-3}$ $\mathrm{mol} / \mathrm{dm}^{3}, 80 \%$ of $\mathrm{SiC}$ is recovered over $\mathrm{pH} 6.0$ as well as the concentration of $9.0 \times 10^{-4} \mathrm{~mol} / \mathrm{dm}^{3}$. Under all the $\mathrm{pH}$ range, $\mathrm{SiO}_{2}$ recovery is less than $30 \%$. The decrease in the recovery of $\mathrm{SiO}_{2}$ is due to the fact that the low concentration of DTMAC like $9.0 \times 10^{-5} \mathrm{~mol} / \mathrm{dm}^{3}$ gives the low surface coverage of the surfactant and this causes the weak adherence of $\mathrm{N}_{2}$ bubbles on particle surface. The effect of solid/liquid ratio for $\mathrm{SiC}$ and $\mathrm{SiO}_{2}$ mixture on flotation was investigated. It was found that the solid concentration less than $10 \%$ gives the $80 \% \mathrm{SiC}$ recovery at any solid concentration, whereas the recovery of $\mathrm{SiO}_{2}$ is less than $10 \%$. Therefore, this is the preferable flotation condition.

\subsection{Flotation Separation Process for SiC}

A series of investigations with cationic surfactants clarified that the flotation with DTMAC makes it possible to separate $\mathrm{SiC}$ from $\mathrm{SiO}_{2}$. Figure 9 shows the flotation separation process of $\mathrm{SiC}$ from the mixture of $\mathrm{SiC}$ and $\mathrm{SiO}_{2}$ with DTMAC. The separation process is composed of the following steps. The float and the sink are separated after flotation of the mixture of $\mathrm{SiC}$ and $\mathrm{SiO}_{2}$ in the roughing step. The float is sent to the cleaning step where the float is recovered as $\mathrm{SiC}$ with high purity. The sink generated in the roughing and cleaning steps is conveyed to the scavenging step, where the float is circulated to the roughing step with feed particles and the sink is recovered as $\mathrm{SiO}_{2}$. In the proposed flotation process, any step is carried out at $\mathrm{pH} 6.0$ which shows good separation of $\mathrm{SiC}$ from $\mathrm{SiO}_{2}$. Table 3 shows the flotation results in the each flotation

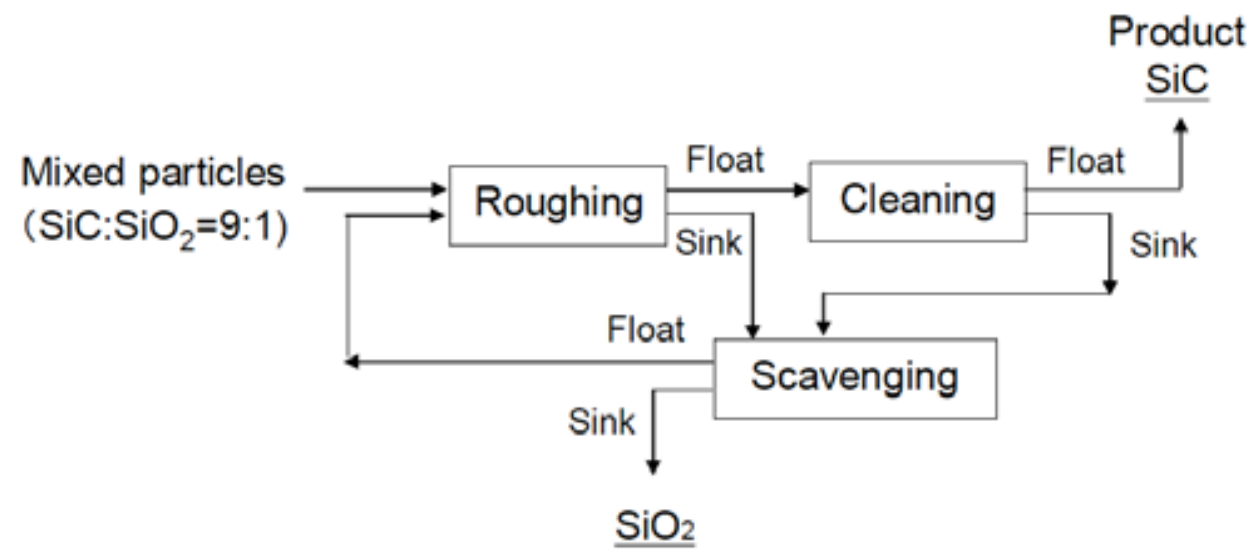

Figure 9: Separation process of $\mathrm{SiC}$ and $\mathrm{SiO}_{2}$.

Table 3: Flotation Recovery of $\mathrm{SiC}$ and $\mathrm{SiO}_{2}$ in Roughing, Cleaning and Scavenging Steps

\begin{tabular}{|c|c|c|c|c|c|}
\hline Step & & $\mathrm{SiC}[g]$ & $\mathrm{SiO}_{2}[\mathrm{~g}]$ & Purity of SiC [\%] & Yield of SiC [\%] \\
\hline \multirow{3}{*}{ Roughing } & Feed & 90 & 10 & 90.0 & - \\
\hline & Float & 77.5 & 1.0 & 98.7 & 86.1 \\
\hline & Sink & 12.5 & 9.0 & 58.1 & - \\
\hline \multirow{3}{*}{ Cleaning } & Feed & 77.5 & 1.0 & 98.7 & - \\
\hline & Float & 67.2 & 0.2 & 99.7 & 86.7 \\
\hline & Sink & 10.3 & 0.8 & 92.8 & - \\
\hline \multirow{3}{*}{ Scavenging } & Feed & 22.8 & 9.8 & 69.9 & - \\
\hline & Float & 19.8 & 0.9 & 95.7 & 86.8 \\
\hline & Sink & 3.0 & 8.9 & 25.2 & - \\
\hline
\end{tabular}

Solid content: 10wt\%, DTMAC concn.: $4.0 \times 10^{-3} \mathrm{~mol} / \mathrm{dm}^{3}$.

Flow rate of $\mathrm{N}_{2}: 200 \mathrm{~cm}^{3} / \mathrm{min}$, Flotation time: $1.5 \mathrm{~min}, \mathrm{pH}: 6.0$. 
step when the solid concentration is $10 \mathrm{wt} \%$. The purity and the recovery of $\mathrm{SiC}$ in the roughing step are $98.7 \%$ and $86.1 \%$, respectively. In the cleaning step, SiC can be obtained as the float with high purity and recovery, e.g. the purity and recovery are $99.7 \%$ and $86.7 \%$, respectively. Concerning the sink in the scavenging step, the purity and recovery of $\mathrm{SiO}_{2}$ are $78.4 \%$ and $90.8 \%$, respectively. The combination of roughing, cleaning and scavenging steps allows recovering $\mathrm{SiC}$ with $99.7 \%$ purity and $96.7 \%$ recovery.

\section{CONCLUSION}

It was clarified that $\mathrm{SiC}$ can be separated from $\mathrm{SiC}$ and $\mathrm{SiO}_{2}$ mixture by flotation if added surfactants strengthen the hydrophobic property of SiC surface. When DTMAC is used as a surfactant, high separation takes place between $\mathrm{SiC}$ and $\mathrm{SiO}_{2}$. Since DTMAC has a longer hydrophobic group among water soluble cationic surfactants, DTMAC can give hydrophobic property by adsorbing on the $\mathrm{SiC}$ particles. As the flotation results for $\mathrm{SiC}$ and $\mathrm{SiO}_{2}$ mixture using DTMAC, the recoveries of $\mathrm{SiC}$ and $\mathrm{SiO}_{2}$ were $80 \%$ and $10 \%$ at $\mathrm{pH} 6.0$, respectively, where the highest separation percentage can be obtained in the single batch test. It was confirmed that the combination of roughing, cleaning and scavenging steps permits to recover $\mathrm{SiC}$ with $99.7 \%$ purity and $96.7 \%$ recovery from the investigation of flotation process. In the scavenging step, $\mathrm{SiO}_{2}$ can be obtained as sink with $74.8 \%$ purity and $90.8 \%$ recovery.

\section{REFERENCES}

[1] Fuerstenau DW. Interfacial Process in Mineral/Water Systems. Pure Appl Chem 1970; 24: 135-64. http://dx.doi.org/10.1351/pac197024010135

[2] Fuerstenau MC. Role of Metal Ion Hydrolysis in Oxide and Silicate Flotation Systems. AIChE Symposium Series, AIChE, New York, U.S.A 1975; vol. 150: pp. 16-23.

[3] Fuerstenau DW, Shibata J. On Using Electrokinetics to Interpret the Flotation and Interfacial Behavior of Manganese Dioxide. Int J Miner Process 1999; 57: 205-17. http://dx.doi.org/10.1016/S0301-7516(99)00018-6

[4] Shibata J, Fuerstenau DW. Flocculation and Flotation Characteristics of Fine Hematite with Sodium Oleate. Int $J$ Miner Process 2003; 72: 25-32. http://dx.doi.org/10.1016/S0301-7516(03)00085-1

[5] Kusaka E, Yano S, Fukunaka Y, Ishii R. Fundamental Study on Separation of Silicon Compound Particles with Flotation (written in Japanese) Proc MMIJ Annual Meeting 2003, Tokyo Japan 2003; II: pp. 83-84.

[6] Yoshikawa M, Kusaka E, Fukunaka Y, Ishii R. Fundamental Study on Column Flotation of Submicron SiC particles. (written in Japanese). Proc MMIJ Annual Meeting 2002, Tokyo, Japan 2002; II: pp. 76-77.

[7] Kaimenkasseizai Bunsekikenkyukai ed.; Analysis Method of Surfactant (Shinpan Kaimenkasseizai Bunsekiho), Miyuki Shobou, Tokyo, Japan 1987; pp. 317-318. 